\title{
Representaciones del cuerpo feme- nino por fotógrafas españolas: una mirada feminista
}

\author{
Representations of female body by spanish female \\ photographers: a feminist viewopoint
}

Karla Liliana Matías Manosalva

Doctora en Comunicación Audiovisual. Universidad Complutense de Madrid

karla134@hotmail.com

Recibido: $24 / 11 / 2014$

Aceptado: $12 / 02 / 2015$

\begin{abstract}
Resumen
Este artículo pretende divulgar la investigación desarrollada en la tesis doctoral "Representaciones del cuerpo femenino por fotógrafas españolas: una mirada feminista", en la que se realizó un estudio que permitió conocer fotografías del cuerpo femenino, creadas por dieciséis fotógrafas españolas, desde el año 1980 hasta 2011, analizando el significado iconográfico, iconológico y feminista que tienen esta clase de imágenes del cuerpo femenino. Las fotógrafas españolas representan una imagen personal y real de lo que es para ellas el cuerpo femenino; desde cómo lo sienten, cómo lo interpretan o cómo el cuerpo de la mujer ha dejado de ser un "objeto pasivo" a ser cimentado desde un contexto de "sujeto". Rechazan (deconstruyen) el icono de un "cuerpo femenino", creado y expuesto desde la perspectiva patriarcal. Rompen con los arquetipos impuestos estableciendo una nueva representación de lo que simboliza su cuerpo.
\end{abstract}

Palabras clave

Fotógrafas, cuerpo femenino, feminismo, fotografía. 


\begin{abstract}
This article aims to disseminate the research conducted for the doctoral thesis "Representations of female body by spanish female photographers: a feminist viewpoint". The research conducted allowed the gathering of photographs of the female form, taken by female Spanish photographers from 1980 to 2011, analyzing the meaning of the images, iconology and feminism that these classes of images of the female form portray. The photographs represent a personal and truthful image which for them is the female form; from how they feel, how they interpret them and how the female body has ceased to be a "passive object" to be that established as a" subject" in context. They reject the icon of a "female body", created and exhibited from a patriarchal perspective. They break away from archetypes imposed thereby creating a new representation of what their body symbolizes.
\end{abstract}

\title{
Keywords
}

Photographers, female body, feminism, photographs.

Referencia normalizada: MATÍAS MANOSALVA, K.L. (2015): “Representaciones del cuerpo femenino por fotógrafas españolas: una mirada feminista". Arte y Ciudad. Revista de Investigación, no 7 (abril), págs. 47-66. Madrid. Grupo de Investigación Arte, Arquitectura y Comunicación en la Ciudad Contemporánea, Universidad Complutense de Madrid.

Sumario: 1. Presentación. 2. Metodología. 2.1 Metodología Feminista. 2.2 Método Iconológico. 3. Fotógrafas Españolas. 3.1 Parámetros de Selección. 3.2 Fotógrafas Seleccionadas. 3.3 Características Generales de las Fotógrafas. 4. Análisis Iconológico y Feminista de las Imágenes Fotográficas. 4.1 Fotografías Analizadas. 5. Conclusiones. 5.1 Conclusiones Generales del Análisis Iconográfico. 5.2 Conclusiones del Análisis Iconológico y Feminista. 6. Referencias bibliográficas.

\section{Presentación.}

Este proyecto nació de la investigación desarrollada para obtener el Diploma de Estudios Avanzados (DEA), titulada "Estado de la cuestión de fotógrafas artísticas españolas. 1980-2008", considerada la primera fase del estudio. A continuación se elabora la tesis doctoral, fundamentada en el trabajo y obra de las fotógrafas españolas. Los objetivos propuestos para el desarrollo de la misma fueron los siguientes: Realizar un estudio que permita conocer foto- 
grafías del cuerpo femenino, desde una perspectiva feminista, creadas por fotógrafas españolas, a partir los años de 1980 hasta 2011. Clasificar a las fotógrafas que desarrollaron su trabajo sobre representaciones del cuerpo femenino, bajo parámetros de selección elaborados de acuerdo a hipótesis propuestas. Analizar el significado iconográfico, iconológico y feminista que tienen esta clase de imágenes del cuerpo femenino. La hipótesis planteada corroboró que en los últimos treinta años, las fotógrafas españolas crearon imágenes del cuerpo femenino, basadas en una perspectiva feminista. Esta conjetura partió de una serie de indagaciones relacionadas con teorías feministas, y con la revisión de la historia de la mujer en la fotografía.

\section{Metodología.}

\subsection{Metodología Feminista ${ }^{1}$.}

Esta metodología ha ido adquiriendo un significado y una implicación dentro de la orientación postmodernista, ya que la imagen de la mujer, especialmente a lo largo de la segunda parte del siglo XX, ha alcanzado una connotación epistemológica y metodológica propia, que ha ido obligando a un rediseño de la mayoría de los proyectos de indagación en que la mujer toma un papel determinante, ya sea como sujeto de la labor investigativa o como objeto prevalente de la misma. La realidad básica que da soporte a una "metodología femenina", es el hecho fundamental de que sea la mujer la participante como investigadora y también como objeto de la investigación. En efecto, es fácil comprender cómo la mujer, conociendo su propio cuerpo, sus problemas de salud, sus vivencias personales, familiares y sociales, está en mejores condiciones metodológicas para comprender a otras mujeres y sus problemas.

\footnotetext{
${ }^{1}$ Según Teresita de Barbieri, en la últimas tres décadas han surgido términos que son, estudios de la mujer, estudios sobre las mujeres, estudios de género y estudios feministas que aplican esta metodología. Por lo tanto es necesario tener claro en qué consiste cada uno. Estudios de la Mujer fue la primera formulación centrada en la caracterización de la población femenina. La investigación dio cuenta de que las condiciones de vida de las mujeres eran muy diferentes en un mismo espacio y tiempo, dando paso a los Estudios sobre las mujeres. Los Estudios de Género enfatizan los aspectos específicos de construcción social y carácter relacional. Y por último, los Estudios Feministas ponen el énfasis en la voluntad política que subyace el análisis de los anteriores, para la superación de la desigualdad en razón de los géneros. Sobre este tema ver Acerca de las propuestas metodológicas feministas, de Teresita de Barbieri.
} 
La profesora María Mies, en su libro Hacia una metodología feminista, expone detalladamente cuáles son las bases más importantes en la metodología feminista:

- Crítica y dialéctica entre el investigador y sus "sujetos" de estudio.

- La "visión desde arriba", ha de ser remplazada por la "visión desde abajo".

- Participación activa en las acciones.

- Cambio del status quo.

- El proceso de investigación debe convertirse en un proceso de "concientización".

\subsection{Método Iconológico.}

En 1939 Panofsky escribe el libro Estudios sobre Iconología y desde entonces su método se ha convertido en uno de los más apropiados para el análisis de las imágenes. En esta publicación Panofsky plantea la explicación del por qué las imágenes se relacionan en un contexto determinado; realzando la importancia de que en la obra de arte la forma no se puede separar de su contenido, ya que las dos consiguen un sentido que lleva a obtener valores simbólicos. Enseña que no sólo hay que estudiar la obra de arte como un elemento estético sino como un hecho histórico, y para poder llevar a cabo esta investigación, el estudio de la obra debe seguir tres pasos:

1. Análisis Pre-iconográfico: Se analiza la obra dentro del campo estilístico ubicándola en el periodo artístico que el tratamiento de sus formas indiquen.

2. Análisis Iconográfico: Analiza los elementos que acompañan a la obra, sus diferentes atributos o características, siguiendo los preceptos que este método impone.

3. Análisis Iconológico: Analiza la obra en su contexto cultural intentando comprender su significado en el tiempo en que se ejecutó.

Estos pasos son generales, al seguirlos se llega al análisis de una imagen, donde es importante conocer a fondo los diferentes conceptos que Panofsky relaciona, estudia y propone para llegar a la construcción de su método iconológico. 


\section{Fotógrafas Españolas.}

Actualmente el panorama de fotógrafas cuenta con una representación bastante considerable tanto a nivel mundial como a nivel de España. Cada vez más, las mujeres artistas, se interesan en el campo de la fotografía y lo abordan desde todos los géneros; por este motivo fue necesario establecer cinco parámetros que permitieron realizar una selección acertada de fotógrafas españolas.

\subsection{Parámetros de Selección.}

Los parámetros fueron establecidos desde un punto de vista personal respecto a los temas de interés a desarrollar en la investigación delimitando el sujeto de estudio. De los cinco parámetros a tratar, todos tienen la misma importancia, aunque si fuera necesaria una estructura jerárquica de los mismos, se adecuaría el orden en que están expuestos:

\subsubsection{Que sean Fotógrafas nacidas en España:}

Este aspecto fue fundamental ya que uno de los objetivos era realizar una selección de fotógrafas españolas que representaran en su obra fotográfica el cuerpo femenino. Tratándose de fotógrafas, la situación geográfica es un lugar de referencia importante para el desarrollo de la profesión, porque en cualquier lugar o país que se realice una investigación de este tema, se hallarán magníficas obras fotográficas y, por supuesto, talentosas fotógrafas. Sin embargo el interés de este estudio se orientó específicamente en realizar una investigación de las fotógrafas que han nacido y realizado su trabajo en España.

\subsubsection{Que sean Fotógrafas Artísticas:}

Este parámetro se realizó con el fin de buscar un interés primordial en aquellas fotógrafas que en su trabajo plasman inquietudes artísticas y creativas. Esto no significa que otras manifestaciones de fotografía como el foto reportaje, la fotografía de moda o fotografía de publicidad, no hayan sido desarrolladas por las fotógrafas, pero sería pertinente abordar estas vertientes en otras investigaciones. Esta investigación se centró en este tipo de fotografía, que establece una relación entre arte y fotografía.

\subsubsection{Que hayan surgido en los años 1980 a 2011:}

El optar por esta época se debió a una serie de factores que hicieron de estos años un tiempo de transición en el país, ya que se estableció la democracia y esto generó cambios en la sociedad española y en la cultura del mismo. “En 
lo referente a la fotografía surge un primer acercamiento de ésta a la sociedad, se incorpora a los planes de estudio de Facultades de Bellas Artes y Ciencias de la Información" (Carabias Álvaro, 2001: 197). En un país que hasta entonces había carecido de tradición historiográfica en este lenguaje, se despierta un reciente interés. Desde los años ochenta, críticos, investigadores, fotógrafos y editores llevan a cabo labores para recuperar la tradición fotográfica, entre ellos las historiadoras Cristina Zelich ${ }^{2}$ y Marie-Loup Sougez. Es por esto que las jóvenes creadoras verán en la fotografía un nuevo lenguaje para expresar sus pensamientos, en una técnica rápida, accesible. El interés de las mujeres en la creación fotográfica aumenta y cada vez se ve que importa a más mujeres, que deciden implantar la fotografía en su obra. Al aplicar este parámetro en la selección se tuvo en cuenta la primera exposición realizada por la artista, y de esta manera se cuenta con un punto de referencia en el inicio de su carrera. Del mismo modo, se escogió este período de tiempo ya que se quiere investigar sobre fotógrafas contemporáneas y estar al tanto de lo sucedido recientemente, la historia actual de las fotógrafas españolas en los últimos 31 años.

\subsubsection{Que en su obra representen imágenes del cuerpo femenino:}

Uno de los principales objetivos de esta investigación fue conocer a mujeres artistas creadoras de fotografías, que desarrollaron una influencia feminista en sus diferentes obras; esto se percibió primero en el hecho de ser mujeres; aunque sea un poco polémico en la actualidad, la orientación de un trabajo artístico realizado por una mujer puede que no tenga nada que ver con un enfoque feminista. Esto es una realidad ya que las mujeres ejecutan trabajos sin lineamientos de este tipo; sin embargo se encontraron artistas, y en este caso fotógrafas, quienes plantean esta cuestión en su trabajo, produciendo representaciones del cuerpo femenino.

\subsubsection{Que hayan expuesto en algún sitio reconocido:}

Como sitio reconocido se incluyen museos, galerías de arte, instituciones privadas y públicas, que cuenten con salas de exposiciones; también se han

2 La artista catalana Cristina Zelich (Barcelona, 1954), que ha organizado varias exposiciones fotográficas, en 1995 afirmó que los documentos fotográficos se infravaloraban, apenas existía un coleccionismo, y ni por parte de la administración como del ámbito universitario se realizaban estudios ni investigaciones. 
tenido en cuenta los festivales de fotografía realizados en el país. Este parámetro permitió conocer cómo está el panorama de la fotografía española a nivel mundial, de esta manera se observó en qué lugares internacionales han expuesto las fotógrafas, quiénes han adquirido sus obras y qué temáticas se presentan en su obra.

\subsection{Fotógrafas Seleccionadas.}

Esta selección incluyó las fotógrafas que cumplen con los parámetros anteriormente expuestos, ordenándose de forma cronológica desde la exposición más antigua a la más reciente ${ }^{3}$ :

- Ouka Leele (Madrid, 1957), Primera Exposición: 1976.

- Mireia Sentís (Barcelona, 1947), Primera Exposición: 1983.

- Ana Torralva (Cádiz, 1957), Primera Exposición: 1985.

- Ana Casas Broda (Granada, 1965), Primera Exposición: 1988.

- Isabel Muñoz (Barcelona, 1951), Primera Exposición: 1989.

- Concha Prada (Puebla de Sanabria, 1963), Primera Exposición: 1990.

- Begoña Montalbán (Bilbao, 1958), Primera Exposición: 1991.

- Julia Montilla (Barcelona, 1970), Primera Exposición: 1995.

- Julia Galán (Castellón, 1963), Primera Exposición: 1996.

- Patricia Dauder (Barcelona, 1973), Primera Exposición: 1999.

- Andrea Costas (Vigo, 1978), Primera Exposición: 2000.

- Naia del Castillo (Bilbao, 1975), Primera Exposición: 2002.

- Ana Matey (Madrid, 1978), Primera Exposición: 2002.

- Isabel Tallos (Madrid, 1983), Primera Exposición: 2002.

- Ixone Sadaba (Bilbao, 1977), Primera Exposición: 2003.

- Laura Torrado (Madrid, 1967), Primera exposición: 2003.

\subsection{Características Generales de las Fotógrafas.}

La gran mayoría de fotógrafas son artistas multidisciplinares, es decir, utilizan también otros medios audiovisuales y artísticos para complementar su obra. Se han involucrado en el campo de la docencia, dictando clases en instituciones educativas del país, aportando sus conocimientos y experiencia a futuras generaciones. Respecto al concepto de la obra, para muchas es de gran

\footnotetext{
${ }^{3}$ Si existen dos o más fotógrafas con el mismo año de aparición se ordena alfabéticamente.
} 
inspiración la naturaleza, y el entorno que las rodea tanto paisajes naturales, como paisajes urbanos, como también temas relacionados con el cuerpo femenino, la búsqueda de la identidad, la critica a la sociedad patriarcal y la critica a la sociedad de consumo.

En lo referente a un aspecto formal de la fotografía, la creación escenográfica, hace énfasis en la proyección de su propia puesta en escena, donde cada fotógrafa tiene en cuenta el vestuario, la localización, la luz y la composición de una escena que evoca una ambiente teatral.

\section{Análisis Iconológico y Feminista de las Imágenes Fotográficas.}

Se han seleccionado 48 imágenes del cuerpo femenino, realizadas por fotógrafas españolas, en grupos de tres imágenes por autora, estableciendo primero un estudio de la evolución de la obra de la artista en relación a los planteamientos feministas, y después los tres niveles de análisis inconográficos planteados por Panofsky4.

- Análisis Pre-iconográfico: Se presentaron las características generales de la imagen fotográfica: Título, autor, fecha de realización, técnica, dimensiones, género y lugar de conservación.

- Análisis Iconográfico: Se analizaron los aspectos formales de la imagen como la composición, planos, tonos, iluminación, perspectiva, profundidad de campo, ángulo de la toma.

- Análisis Iconológico: Análisis de la fotografía en su contexto cultural intentando comprender su significado y la correspondencia con el período en que se elaboró. Se relacionaron todos los elementos expuestos en el primer punto de este análisis, para con ello llegar a la interpretación de la imagen, es decir, a su significado total, qué quiso transmitir la artista y qué representa cada símbolo de la imagen. Se indagó su significado en un contexto social e histórico y se planteó la imagen no como una obra que comprende tan solo un análisis estético sino como una imagen relacionada con el contexto cotidiano en que vive la fotógrafa.

\footnotetext{
${ }^{4}$ En este análisis se pretende relacionar tres aspectos fundamentales de las fotografías como son el aspecto técnico, formal, y el más importante que es el referente a la iconología de la obra, que sería el aspecto conceptual.
} 


\subsection{Fotografías Analizadas.}

\section{Generoso Encuentro Con La Belleza Original, Ouka Leele}

La fotografía muestra un cuerpo que no va con el ideal de belleza clásico, al que Leele considera como otro tipo de belleza, donde legitima esta representación de enfoque feminista, ya que se relaciona con las teorías planteadas por el feminismo de la diferencia, revelando a una mujer con un cuerpo que no es considerado bello ni atractivo por los cánones de belleza patriarcales. Presenta una mujer que no está insatisfecha de su cuerpo, que no tiene miedo de exponerlo al espectador.

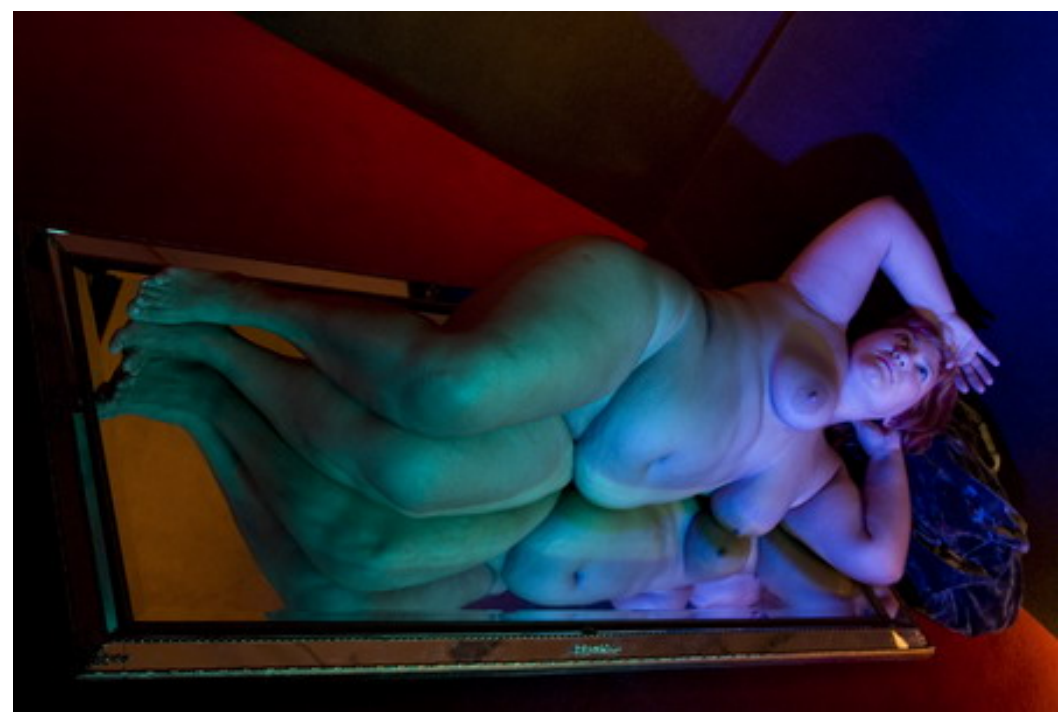

Fig. 1. Ouka Leele, Generoso encuentro con la belleza original, 2007. Fuente: http://www.mecd.gob.es/cultura-mecd/eu/areas-cultura/promociondelarte/exposiciones/progexposiciones-itinerantes/exposiciones-itinerantes-disponibles/oukaleele-inedita.html

\section{Máxima Audiencia, Mireia Sentís.}

En esta imagen la artista narra lo que significan para ella los medios de comunicación de masas. En este caso específico el de la televisión. Generando tensión y estimulando al espectador para que éste se implique en una escena que constituye el poder de la televisión. La imagen cuenta con un enfoque feminista, cuestionando cómo los medios de comunicación presentan un estereotipo de cuerpo femenino. 


\section{Carmen Cortés, Ana Torralva.}

Retrato que concede protagonismo al gesto corporal, involucrando la figura en movimiento de la bailaora, donde Torralva presenta a una mujer notable, no estereotipada, ni objetualizada, ni resignada, que no cumple los arquetipos instituidos por el patriarcado; por medio de esta imagen se vislumbra una mujer con una fuerte personalidad.

\section{Leche, Ana Casas Broda.}

Fotografía que surge de la necesidad de Ana Casas de contar cómo cambio su cuerpo cuando estuvo embarazada; apropiándose de sus senos, busca transmitir al espectador esa emoción que fue para ella el sentir que con sus pechos iba a alimentar a sus hijos. Imagen que busca reivindicar el cuerpo de la mujer embarazada.

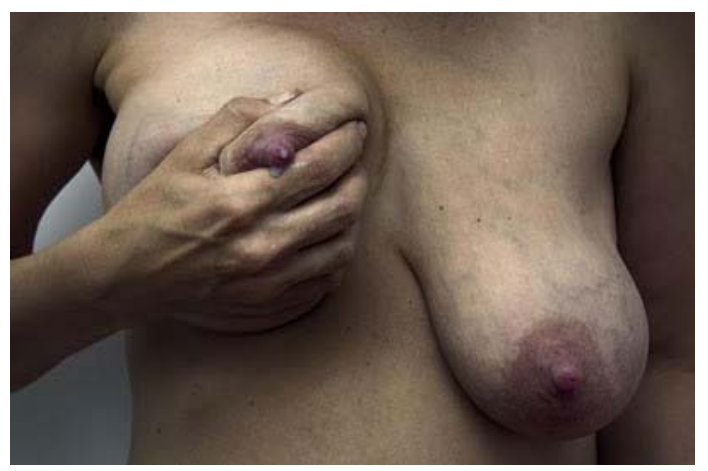

Fig. 2. Ana Casas, Leche, 2008. Fuente: http://www.anacasasbroda.com/\#!19akinderwunsch-/cpi5

\section{Fragmentos, Isabel Muñoz.}

Muñoz presenta una imagen donde la búsqueda de la ambigüedad en el cuerpo del ser humano es esencial; lo elemental es permitir que el espectador interprete. La confusión de las formas abstractas del cuerpo femenino y masculino en esta imagen es la representación del equilibrio y la armonía del mismo.

\section{Basuras Domésticas, Concha Prada.}

Fotografía donde Prada se apropia de un espacio íntimo y lo convierte en una escena cotidiana, de la que no siente vergüenza ni pudor. Se presenta al espectador una imagen definitiva, que exterioriza una gran corporalidad frente 
a los límites de un segmento de cuerpo, y al mismo tiempo se deconstruye un canon de lo que se debería enseñar o no en una fotografía 5 .

\section{Espacios Reservados, Begoña Montalbán.}

La fotografía presenta un maniquí, totalmente inerte, donde la orientación feminista se enfoca en una reflexión profunda de los métodos quirúrgicos o procedimientos genéticos, los cuales construyen un cuerpo de mujer a la carta. Un cuerpo modificado y arreglado relaciona esta imagen de Montalbán con los principios del ciberfeminismo, y sobre todo con el concepto de "Cyborg" planteado por Haraway, quien lo define como una nueva figuración simbólica de la subjetividad femenina.

\section{Ofelia, Julia Montilla.}

Fig. 3. Julia Montilla, Ofelia, de la serie "Chroma Key", 1997, fotografía 1 de 4 . Fuente: http://www.juliamontilla.com/ work/chroma-key/

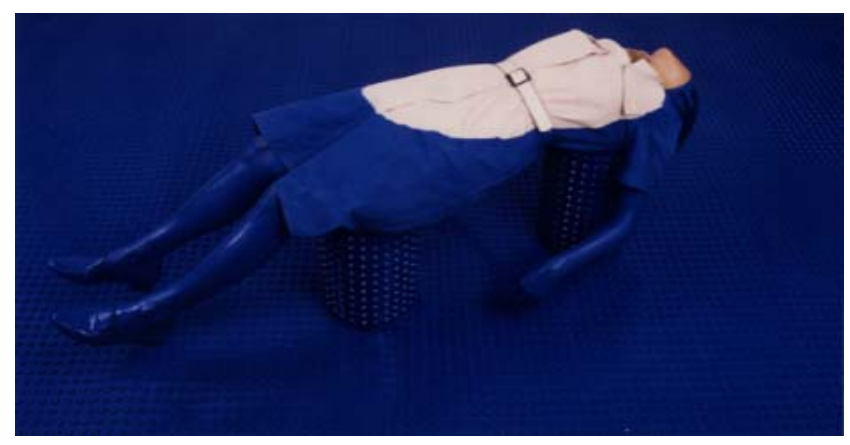

Imagen que ubica al espectador en una configuración espacial virtual, donde la perspectiva feminista de esta imagen se ve en la creación de la misma ya que Montilla crea un espacio implantado por una técnica audiovisual en un ordenador: Un lugar inventado, donde sitúa a una mujer llamada Ofelia ${ }^{6}$, que en divergencia con el espacio ficticio, es una mujer real de carne y hueso. Ofe-

\footnotetext{
${ }^{5}$ Esta fotografía hace referencia al concepto de arte abyecto propuesto por Julia Kristeva, quien describe la expulsión de lo considerado abyecto como una condición necesaria para la formación sexual, psicológica y social de la identidad. En un sentido general, el concepto abarca obras que usan fluidos corporales o aluden a ellos, A pesar de sus diferentes lenguajes, estos artistas desafían al público mediante lo feo y lo horrendo. Así, el término arte abyecto se puede aplicar a aquellas obras que muestran lo que se llamará "el lado trasero" del arte, especialmente, del arte moderno. Ver más de este tema en su libro Poderes de la perversión.

${ }^{6}$ Ofelia se inspira en el personaje creado por Shakespeare, quien decide suicidarse y muere ahogada, debido que no soporta la trágica situación con su amado Hamlet.
} 
lia ha sido un personaje femenino creado por pintores masculinos, quienes siempre la han idealizado. La Ofelia de Montilla pese a estar atrapada en un entorno para nada real, se muestra ante el espectador como una mujer normal, de esta época, de cabello oscuro, nada que hace referencia con el estereotipo de belleza con que se ha creado el personaje de cuento.

\section{Silencio, Julia Galán.}

En esta imagen Galán realiza una denuncia social y crítica, ya que enseña a una persona que está siendo obligada a callar, haciendo visible una situación llena de represión hacia personas vulnerables. Representa situaciones que afectan tanto a la mujer como al ser humano, trata de transmitir esa conciencia social al espectador, ya que es importante para ella hacer visible una situación cargada de violencia y represión, como la que se vislumbra en esta imagen.

\section{Identidades, Patricia Dauder.}

La imagen de Patricia Dauder explora la construcción de la apariencia, que lleva a formar la identidad por medio de un rostro femenino, transformado. Cambiando sus rasgos originales, haciendo énfasis a una clara perspectiva feminista, ya que increpa claramente el uso del maquillaje. Esta imagen tiene un enfoque feminista contemporáneo, ya que critica directamente el uso del maquillaje $\mathrm{e}^{7}$ y la cirugía estética, en un rostro que termina deformándose y perdiendo su autentica identidad.

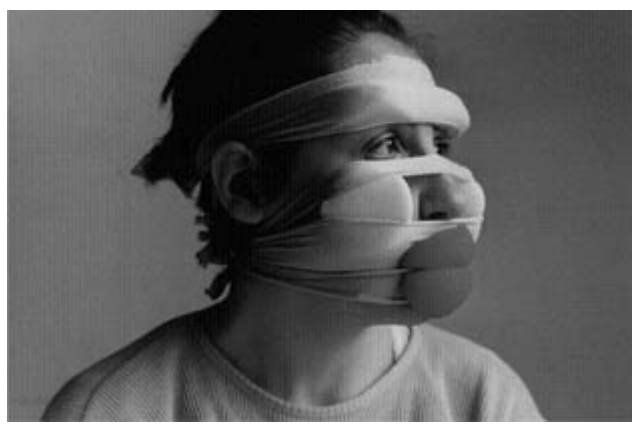

Fig. 4. Patricia Dauder, Identidades, 1998.

Fuente: http://patriciadauder.net/w/2010-2014/

\footnotetext{
${ }^{7}$ Como ha señalado John Pultz en su libro La fotografía y el cuerpo: La feminidad suele asociarse con la mascarada, la falsa representación, la simulación y la seducción, ya que la mujer hace uso de una serie de artificios como el maquillaje, la indumentaria o los cambios en el cabello. Pág.76.
} 


\section{Tiempo al tiempo, Andrea Costas.}

Imagen que presenta dos medias caras, que se complementan pero están separadas por el paso del tiempo, que es lo que diferencia un rostro de otro. Se evidencia un enfoque feminista en una situación íntima y esencial, donde la artista relaciona el paso del tiempo, tanto en su rostro como en el de su abuela; al mismo tiempo legitima el rostro de su abuela, que no cumple el canon de belleza impuesto por el sistema patriarcal, el cual hizo creer que solo las mujeres jóvenes y sin arrugas en la cara eran las que podían posar ante una fotografía. Pensamiento refutado por Costas, quien pone a su abuela enfrente de la cámara creando una imagen llena de poética visual, en la que la experiencia y la sabiduría de su abuela contrasta con la juventud y el sentimiento de esperanza que refleja Costas.

\section{Diálogos I, Naia del Castillo.}

En esta fotografía se observa la cabellera de dos mujeres, en las que no se reconoce ningún gesto de sus caras, ya que esta melena cubre sus rostros, creando el caos en el que se ven envueltas las dos mujeres, donde sus cabelleras se fusionan pero al mismo tiempo se repelen. La imagen deconstruye el significado habitual de la cabellera femenina orientándose en una representación existencial que transciende a los problemas de la mujer como sujeto.

Fig. 5. Naia del Castillo, Diálogos I, 2000, fotografía 7 de 9. Fuente: http://naiadelcastillo.com /atrapados_eng.php

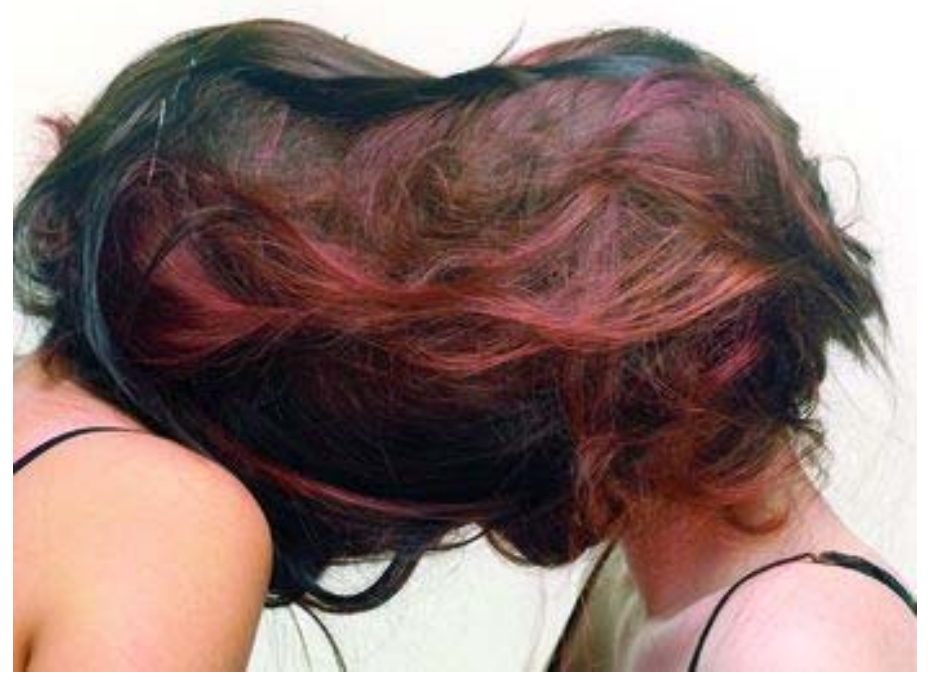




\section{Soy espinaca, Ana Matey.}

Esta imagen basada en una acción performática realizada por Matey enfocándose en la búsqueda de su identidad, donde se vale de su cuerpo cuestionándose qué clase de cuerpo es el suyo. Se pregunta quién es y por medio de su cuerpo va contestando esta pregunta, donde no deja de sentir su cuerpo atrapado y nada libre. La espinaca congelada es una metáfora de cómo la sociedad crea y manipula el cuerpo.

\section{Incúbitas, Isabel Tallos.}

La imagen de Tallos presenta estancias ocupadas por una mujer que espera y se asfixia. Un mismo cuerpo que se repite en un espacio despojado que pone en conexión la nada y el absoluto. En el centro, la mujer, donde implícitamente se expone a una crítica de la alienación existente que ostenta el cuerpo en la sociedad contemporánea.

\section{Poética de la Desaparición, Ixone Sadaba.}

En la fotografía se observa el cuerpo esfumado de Ixone, desapareciendo, un cuerpo de mujer que está a punto de evaporarse. Esta fotografía presenta una lectura feminista donde la exposición del propio cuerpo de la artista, y el hablar claro a través del mismo, genera una condición política primordial, así como la representación inmediata de expresión de la propia identidad.

\section{Masculinos, Laura Torrado.}

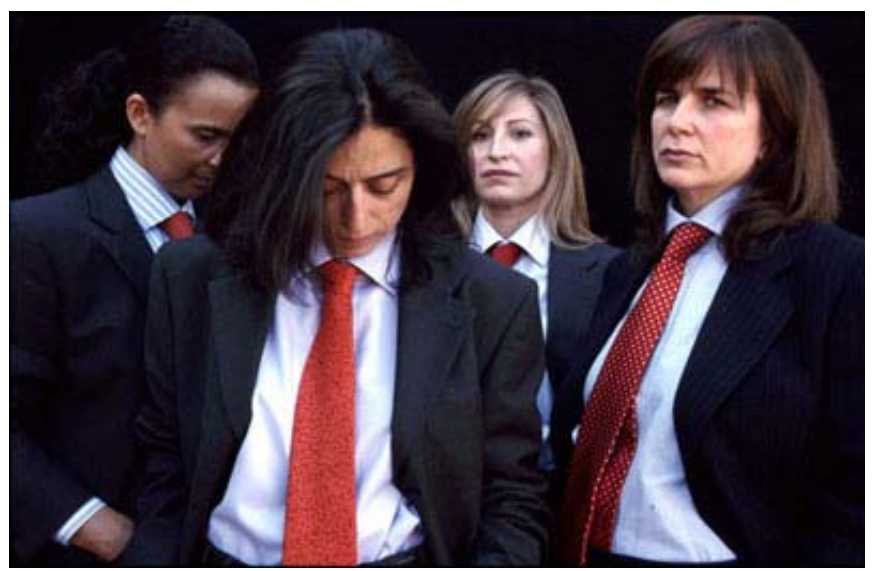

Fig. 6. Laura Torrado, Masculinos, 2007. Fuente: http://www.lauratorrado. net/hammams.htm\# 
La fotografía pretende ir más allá de ambicionar disfrazar a cuatro mujeres con ropa de hombre; quiere presentar una narrativa que elude los relatos conocidos para orientarse en lo que queda por decir desde una perspectiva no habitual, donde los temas abordados en esta imagen son el género, el cuerpo y la identidad. La imagen plantea la perspectiva feminista desde el punto que invierte el orden establecido en lo referente al uso de la vestimenta en los géneros.

\section{Conclusiones.}

Como resultado de la investigación se verificó la hipótesis planteada por medio del análisis iconológico y feminista que incluyó la obra de dieciséis fotógrafas españolas. En los últimos 30 años, las fotógrafas españolas realizaron imágenes del cuerpo femenino, estructurándose en un enfoque feminista. Estas imágenes del cuerpo femenino dejan atrás estereotipos establecidos en el transcurso de la historia de la fotografía, como son la idealización y objetualización del cuerpo, teniendo en cuenta que hay un cambio evidente en la forma del mismo, que involucra la mirada femenina. Es decir que se da el paso de dejar de ser el objeto de la fotografía, a ser sujeto, tanto en la creación como en la representación, siendo esta representación subjetiva, personal y no idealizada. Se otorga gran relevancia a la fotografía española y específicamente a la fotografía hecha por mujeres, a partir de la contextualización de un método iconológico-feminista, enfocado a elementos del lenguaje fotográfico, permitiendo el análisis de las diversas fotografías recopiladas para esta investigación.

\subsection{Conclusiones Generales del Análisis Iconográfico.}

Teniendo en cuenta los elementos del lenguaje fotográfico utilizados en el análisis iconográfico, se deduce de las 48 imágenes lo siguiente:

- En la imagen predomina la composición abierta aunque en algunas fotografías se ve una composición de la imagen jerárquica.

- En lo relativo a los planos de la imagen es frecuente ver fotografías de dos y tres planos.

- En la mayoría de las fotografías se observan tonos blanco y negro, ya que fueron tomadas con película a blanco y negro, donde se aprecia la escala de grises al completo desde el más oscuro hasta el más claro. En relación al color predominan los tonos neutros, ni cálidos ni fríos. 
- La iluminación de las mismas se enfoca en la luz principal, suave, difusa, que se presenta la mayoría de veces como una luz frontal, y en pocas ocasiones se presenta una luz lateral. Imágenes con poca sombra.

- La perspectiva que domina es la atmosférica aunque también se presentan imágenes con perspectiva lineal.

- La profundidad de campo más usada es larga o amplia, por lo tanto se deduce que se usó un diafragma cerrado, lo que genera nitidez en la imagen. Sin embargo alguna imagen presenta el diafragma abierto, lo que genera un leve desenfoque.

- Respecto al ángulo de la toma domina el ángulo normal o de 90 grados, sin ninguna inclinación, aunque también se ven contrapicados, picados, o picado inclinado.

- En lo referente al aspecto formal de estas fotografías cabe anotar que en lo concerniente a la creación escenográfica de la misma todas las fotógrafas del análisis han creado su propia puesta en escena, donde tienen en cuenta el vestuario de las modelos, la locación, la luz y la composición de la escena; el resultado refleja una imagen donde cada detalle es pensado y no improvisado. Se deduce que estas fotógrafas van más allá de una simple toma fotográfica y se remiten a crear y pensar la poética de la imagen, donde se conjugan y son igualmente relevantes los aspectos técnicos de la fotografía como su significado y concepto.

- En el análisis se encontraron 17 imágenes en blanco y negro, 31 imágenes a color, 16 imágenes analógicas y 32 imágenes digitales.

\subsubsection{Conclusiones del Análisis Iconológico y Feminista.}

En cuanto al aspecto iconológico y feminista, las imágenes analizadas presentaron rasgos comunes como es el desarrollo de una problemática específica que se refiere a poner en evidencia una situación particular del personaje que aparece en la fotografía. Es decir, en las 48 imágenes se hace alusión a cierta problemática que las artistas han experimentado desde su vivencia personal, sin dejar de lado influencias externas como la sociedad que las rodea. Así mismo, es importante señalar que en todas las imágenes se contextualiza una problemática de la época actual. De la misma manera, las fotógrafas asumen que la obra se completa al ser vista e interpretada subjetivamente por el espectador. Los temas que se vieron desarrollados en las 48 imágenes son: 
- Representaciones del cuerpo femenino, desde un nivel íntimo y personal. Mirada propia de la artista.

- Búsqueda de la identidad femenina por medio del lenguaje visual.

- Crítica a la sociedad patriarcal.

- Deconstrucción por medio de una fotografía del modelo androcéntrico.

- Crítica a la sociedad de consumo.

- Crítica a los estereotipos del cuerpo femenino creados por los medios de comunicación de masas.

- Crítica al maquillaje y las cirugías plásticas.

- Reflexión acerca de cuestiones y sentimientos muchas veces personales.

- Recontextualización de situaciones o personajes de épocas anteriores, o cuentos, otorgándoles una nueva lectura que se adecua a la época actual.

- Acercamiento a personas de la familia, en relación al cuerpo.

- Reivindicación de mujeres de diversas culturas.

- Interés en temas que tienen que ver con tareas domésticas.

- El cuerpo construido desde las nuevas tecnologías.

- El cuerpo maltratado de algunas mujeres.

- El cuerpo sometido y asfixiado de otras.

- Muchas veces la construcción de la fotografía parte de la ejecución de una acción o performance.

- Nuevas propuestas visuales para darle un nuevo significado al cuerpo femenino en las fotografías. Éstas se adecuan a las propuestas del arte contemporáneo, donde el cuerpo viene siendo el protagonista de gran cantidad de obras.

- Rechazo a las instituciones que oprimen el cuerpo y a los cánones tradicionales de representación.

\section{Bibliografía.}

Alario Trigueros, María Teresa. (2008): Arte y feminismo. Nerea. DonostiaSan Sebastián.

AliagA, Juan Vicente. (2004): Arte y cuestiones de género: una travesía del siglo XX. Nerea. Madrid.

AliaGA, Juan Vicente. (2007): Orden fálico: androcentrismo y violencia de género en las prácticas artísticas del siglo XX. Akal. Tres Cantos. 
BARTHES, Roland. (1982): La cámara lúcida: Nota sobre la fotografía. Editorial Gustavo Gili. Barcelona.

BEguiristain, María Teresa. (1998): “Aportaciones del movimiento feminista al arte contemporáneo". En Crítica cultural y creación artística: Coloquios contemporáneos. Consejería de Cultura, Educación y Ciencia, Dirección General de Promoción Cultural, Museos y Bellas Artes. Valencia.

BENJAMin, Walter. (2008): Sobre la fotografía. Pre-Textos. Valencia.

BERGER, John. (2006): Sobre las propiedades del retrato fotográfico. Editorial Gustavo Gili. Barcelona.

BERGER, John. (2006): Modos de Ver. Editorial Gustavo Gili. Barcelona.

DE BARBIERI, Teresita (1998): “Acerca de las propuestas metodológicas feministas". En: Eli Bartra (Comp.) Debates en torno a una metodología feminista. Universidad Autónoma Metropolitana. México.

CARABiAs Álvaro, Mónica. (2001): “Códigos para la autorepresentación femenina en la fotografía española de los 90". En Geografías de la mirada: género, creación artística y representación. MARIÁN LÓPEZ F. CAO (ed.) Madrid. Instituto de Investigaciones Feministas de la Universidad Complutense de Asociación Cultural A-Mudayna. Madrid.

DiEGo Otero, Estrella De. (1992): El andrógino sexuado: eternos ideales, nuevas estrategias de género. Visor. Madrid.

ESTRADA, Ángela Ma. MiLlán, Carmen. (2004): Pensar en género. Teoría y prácticas para nuevas cartografías del cuerpo. Pontificia Universidad Javeriana. Bogotá.

KRAUSS, Rosalind. (2002): Lo fotográfico: por una teoría de los desplazamientos. Gustavo Gili. Barcelona.

MIES, Maria. (1999): Towards a methodology for feminist research. Sage. Londres.

Museo De Arte Contemporáneo "Esteban Vicente”. (2005): Miradas de mujer: 20 fotógrafas españolas. Segovia.

NoCHLIN, Linda. (1989): Women, art and power: and other essays. Boulder (Colorado). Oxford.

PANOFSKY, Erwin. (1979): El significado en las artes visuales. Alianza Editorial. Madrid.

PANOFSKY, Erwin. (1972): Estudios sobre iconología. Alianza Editorial. Madrid. 
RAMIREZ, Juan Antonio. (2003): Corpus Solus. Para un mapa del cuerpo en el arte contemporáneo. Ediciones Siruela. Madrid.

REINHARZ, Shulamit. (1992): Feminist methods in social research. Oxford University Press. New York.

SoUgEZ, Marie-Loup. (2004): Historia general de la fotografía. Cátedra. Madrid.

\section{Webgrafía.}

Entre fotos. Asociación para la promoción y divulgación de la fotografía. Última Visita: 20-11-2014. http://www.entrefotos.net/

European Society for the history of Photography. Última Visita: 20-11-2014. http://www.donauuni.ac.at/en/department/bildwissenschaft/partnerlinks/e shph/index.php

Fotografía, promoción del arte. Última Visita: 20-11-2014. http://www.mcu.es/ promoArte/CE/Fotografia/Fotografia.html

Guía de la fotografía Artística en España. Última Visita: 20-11-2014. http://www.fotoguia.es/ControlLogin

Photo España. Última Visita: 20-11-2014. http://www.phedigital.com/

Real Sociedad Fotográfica. Última Visita: 20-11-2014. http://www.rsf.es/

Revista PhotoVision. Última Visita: 20-11-2014. http://www.photovision.es/ photovision/portada/index2.html

CASAS, Ana. Última Visita: 20-11-2014. http://www.anacasasbroda.com/

DEL CASTILLO, Naia. http://www.naiadelcastillo.com/ Última Visita: 20-112014.

GALAN, Julia. Última Visita: 20-11-2014. http://www.juliagalan.com/

LEELE, Ouka. Última Visita: 20-11-2014. http://www.oukaleele.com/

MATEY, Ana. Última Visita: 20-11-2014. http://www.anamatey.com/

MONTALBAN, Begoña. http://www.begonamontalban.com/ Última Visita: 20-11-2014.

MONTILLA, Julia. http://www.juliamontilla.com/ Última Visita: 20-11-2014.

MUÑOZ, Isabel. Última Visita: 20-11-2014. http://www.isabelmunoz.es/

PRADA, Concha. Última Visita: 20-11-2014. http://www.conchaprada.com/ 
TALLOS, Isabel. Última Visita: 20-11-2014. http://www.isabeltallos.com/

TORRADO, Laura. http://lauratorrado.net/home.htm Última Visita: 20-112014. 